\title{
Intensive Behavioral Treatment for Children With Autism: Four-Year Outcome and Predictors
}

\author{
Glen O. Sallows and Tamlynn D. Graupner \\ Wisconsin Early Autism Project (Madison)
}

\begin{abstract}
Twenty-four children with autism were randomly assigned to a clinic-directed group, replicating the parameters of the early intensive behavioral treatment developed at UCLA, or to a parent-directed group that received intensive hours but less supervision by equally well-trained supervisors. Outcome after 4 years of treatment, including cognitive, language, adaptive, social, and academic measures, was similar for both groups. After combining groups, we found that $48 \%$ of all children showed rapid learning, achieved average posttreatment scores, and at age 7 , were succeeding in regular education classrooms. Treatment outcome was best predicted by pretreatment imitation, language, and social responsiveness. These results are consistent with those reported by Lovaas and colleagues (Lovaas, 1987; McEachin, Smith, \& Lovaas, 1993).
\end{abstract}

Behavioral approaches for addressing the delays and deficits common in autism have been recognized by many as the most effective treatment methods to date (Green, 1996; Maine Administrators of Service for Children With Disabilities, 2000; New York State Department of Health, 1999; Schreibman, 1988; Smith, 1993). The intervention developed at UCLA in the 1960s and 1970s is perhaps the best known and best documented (e.g., Dawson \& Osterling, 1997; Green, 1996; Smith, 1993). Building on earlier research (e.g., Lovaas, Koegel, Simmons, \& Long, 1973), Lovaas and staff of the UCLA Young Autism Project (1970 to 1984) began treatment with children under 4 years of age using a curriculum emphasizing language development, social interaction, and school integration skills. After 2 to 3 years of treatment, $47 \%$ of the experimental group (9 of 19 children) versus $2 \%$ of the comparison group ( 1 of 40 children) were reported to have achieved "normal functioning" (Lovaas, 1987; McEachin et al., 1993).

These findings demonstrated that many children with autism could make dramatic improvement, even achieve "normalcy," and many re- searchers now agree that intensive behavioral treatment can result in substantial gains for a large proportion of children (e.g., Harris, Handleman, Gordon, Kristoff, \& Fuentes, 1991; Mundy, 1993). However, the UCLA findings also created considerable controversy, and the studies were criticized on methodological and other grounds (e.g., Gresham \& MacMillan, 1998; Schopler, Short, \& Mesibov, 1989). One criticism was that the UCLA group used the term recovered to describe children who had achieved IQ in the average range and placement in regular classrooms. Mundy (1993) suggested that children diagnosed with high functioning autism might achieve similar outcomes and pointed out that several of the recovered children in the follow-up study of the UCLA children at age 13 (McEachin et al., 1993) had clinically significant scores on some behavioral measures. The UCLA team responded by noting that (a) evaluators blind to background information had not identified the recovered children as different from neurotypical children and (b) a few elevated scores may not imply abnormality because several of the neurotypical peers had them as well (Smith, McEachin, \& Lovaas, 1993). Questions were also 
raised regarding whether or not the UCLA results could be fully replicated without the use of aversives, which were part of the UCLA protocol, but are not acceptable in most communities (Schreibman, 1997). Some have questioned the feasibility of implementing the program without the resources of a university research center to train and supervise treatment staff (Sheinkopf \& Siegel, 1998) and to help defray the cost of the program, which, due to the many hours of weekly treatment, can exceed $\$ 50,000$ per year (although it has been argued that the cost of not providing treatment may be much greater over time: Jacobson, Mulick, \& Green, 1998). Finally, because only about half of the children showed marked gains, the need for predictors to determine which children will benefit has been raised (Kazdin, 1993). Lovaas and his colleagues responded to these and other criticisms (Lovaas, Smith, \& McEachin, 1989; Smith et al., 1993; Smith \& Lovaas, 1997), but agreed with others that replication and further research were necessary.

There have now been several reports of partial replication without using aversives (Anderson, Avery, Di Pietro, Edwards, \& Christian, 1987; Birnbrauer \& Leach, 1993; Eikeseth, Smith, Jahr, \& Eldevik, 2002; Smith, Groen, \& Wynn, 2000). Most found, as did Lovaas and his colleagues, that a subset of children showed marked improvement in IQ. Although fewer children reached average levels of functioning, the treatment provided in these studies differed from the UCLA model in several ways (e.g., lower intensity and duration of treatment, different sample characteristics and curriculum, and less training and supervision of staff).

Anderson et al. (1987) provided 15 hours per week for 1 to 2 years (parents provided another 5 hours) and found that 4 of 14 children achieved an IQ over 80 and were in regular classes, but all needed some support. Birnbrauer and Leach (1993) provided 19 hours per week for 1.5 to 2 years and found that 4 of 9 children achieved an IQ over 80 (classroom placement was not reported), but all had poor play skills and self-stimulatory behaviors. The authors noted, however, that their treatment program had not addressed these areas. Smith et al. (2000) provided 25 hours per week for 33 months and reported that 4 of 15 children achieved an IQ over 85 and were in regular classes, but one had behavior problems. The authors noted that their sample had an atypically high number of mute children, 13 of 15 , consid- erably higher than the commonly cited figure of 50\% (Smith \& Lovaas, 1997), and they hypothesized that this was the reason for the relatively low number of children functioning in the average range following treatment. Eikeseth et al. (2002) provided 28 hours per week for 1 year. In their sample, 7 of 13 children with pretreatment IQ over 50 achieved IQ over 85 and were in regular classes with some support. Data beyond the first year have not yet been reported.

Four groups of investigators discussed results based on behavioral treatment in classroom settings, which typically include a mix of $1: 1$ treatment and group activities, so that time in school may not be comparable to hours reported in home-based studies. Following 4 years of treatment, Fenske, Zalenski, Krantz, and McClannahan (1985) found that 4 of 9 children were placed in regular classes. However, neither preposttreatment test scores nor amount of support in school were reported. Harris et al. (1991) provided 5.5 hours per day in class and instructed parents to provide an additional 10 to 15 hours at home (no data were collected on actual hours parents provided). After 1 year of treatment, 6 of 9 children achieved IQ over 85, but were still in classes for students with learning disabilities. A later report (Harris \& Handleman, 2000) found that 9 of 27 children achieved IQ over 85 and were placed in regular classes (time in treatment was not reported), but most required some support. Meyer, Taylor, Levin, and Fisher (2001) provided 30 hours of class time per week for at least 2 years and reported that 7 of 26 children were placed in public schools after 3.5 years of treatment, but 5 required support services. Pre-post IQ was not reported. Romanczyk, Lockshin, and Matey (2001) provided 30 hours of class time per week for 3.3 years and reported that 15\% of the children were discharged to regular classrooms. No information on posttreatment test scores or the need for supports was provided.

In two studies researchers examined the effects of behavioral treatment for children with low pretreatment IQ. Smith, Eikeseth, Klevstrand, and Lovaas (1997) provided children who had pretreatment IQ less than $35(M=28)$ with 30 hours per week for 35 months and reported an increase in IQ of 8 points (3 of 11 children achieved increases of over 15 points) and 10 of 11 achieved single-word expressive speech. Eldevik, Eikeseth, Jahr, and Smith (in press) provided children who had an average pretreatment IQ of 41 with 22 
hours per week of 1:1 treatment for 20 months and reported an increase in IQ of 8 points and an increase in language standard scores of 11 points.

In three studies researchers examined results of behavioral treatment provided by clinicians working outside university settings in what has been termed parent-managed treatment because parents implement treatment designed by a workshop consultant, who supervises less frequently (e.g., once every 2 to 4 months) than the supervision that occurs in programs supervised by a local autism treatment center (e.g., twice per week). Sheinkopf and Siegel (1998) reported results for children who received 19 hours of treatment per week for 16 months supervised by three local providers. Six of 11 children achieved IQ over 90 and 5 were in regular classes, but still had residual symptoms. However, these children may not be comparable to high achievers in other studies because intelligence tests included the Merrill-Palmer, a measure of primarily nonverbal skills, known to yield scores about 15 points higher than standard intelligence tests that include both verbal and nonverbal scales. In the second study, Bibby, Eikeseth, Martin, Mudford, and Reeves (2002) described results for children who received 30 hours of treatment per week (range $=14$ to 40 ) for 32 months (range $=17$ to 43 ) supervised by 25 different consultants, who saw the children several times per year (median $=4$, range $=0$ to 26). Ten of 66 children achieved IQ over 85, and 4 were in regular classes without help. However, as the authors noted, their sample was unlike UCLA's in several ways: $15 \%$ had a pretreatment IQ under 37, 57\% were older than 48 months, many received fewer than 20 hours per week, $80 \%$ of the providers were not UCLA-trained, and no child received weekly supervision. Weiss (1999) reported the results of a study in which children did receive high hours: 40 hours of treatment per week for 2 years. She saw each child every 4 to 6 weeks, reviewed videos of their performance every 2 to 3 weeks, and spoke with parents weekly. Following treatment, 9 of 20 children achieved scores on the Vineland Applied Behavior Composite $(A B C)$ of over 90, were placed in regular classes, and had scores on the Childhood Autism Rating Scale in the nonautistic range (under 30 ). No preor posttreatment IQ data were reported.

Several researchers have described pretreatment variables that seem to predict (are highly correlated with) later outcome. Although findings have not always been consistent, the most com- monly noted predictors have been IQ (Bibby et al., 2002; Eikeseth et al., 2002; Goldstein, 2002; Lovaas, 1987; Newsom \& Rincover, 1989), presence of imitation ability (Goldstein, 2002; Lovaas \& Smith, 1988; Newsom \& Rincover, 1989; Weiss, 1999), language (Lord \& Paul, 1997; Venter, Lord, \& Schopler, 1992), younger age at intervention (Bibby et al., 2002; Fenske et al., 1985; Goldstein, 2002; Harris \& Handleman, 2000), severity of symptoms (Venter et al., 1992), and social responsiveness or "joint attention" (Bono, Daley, \& Sigman, 2004; L. Koegel, Koegel, Shoshan, \& McNerney, 1999; Lord \& Paul, 1997).

Multiple regression has been used to determine combinations of pretreatment variables with strong relationships with outcome. Goldstein (2002) reported that verbal imitation plus IQ plus age resulted in an $R^{2}$ of .78 with acquisition of spoken language. Rapid learning during the first 3 or 4 months of treatment has also been associated with positive outcome (Lovaas \& Smith, 1988; Newsom \& Rincover, 1989; Weiss, 1999). Weiss reported that rapid acquisition of verbal imitation plus nonverbal imitation plus receptive instructions resulted in an $R^{2}$ of .71 with Vineland $\mathrm{ABC}$ and .73 with Childhood Autism Rating Scale scores 2 years later.

We designed the present study to examine several questions. Can a community-based program operating without the resources, support, or supervision of a university center, implement the UCLA program with a similar population of children and achieve similar results without using aversives? Do significant residual symptoms of autism remain among children who achieve posttreatment test scores in the average range? Can pretreatment variables be identified that accurately predict outcome? We also examined the comparative effectiveness of a less costly parent-directed treatment model.

\section{Method}

\section{Participants}

Researchers at the Wisconsin site worked in collaboration with and observed the guidelines set by the National Institutes of Mental Health (NIMH) for Lovaas' Multi-Site Young Autism Project. Children were recruited through local birth to three (special education) programs. All children were screened for eligibility according to the following criteria: (a) age at intake between 24 and 42 months, (b) ratio estimate (mental age 
[MA] divided by chronological age [CA]) of the Mental Development Index of 35 or higher (the ratio estimate was used because almost all children scored below the lowest Mental Development Index of 50 from the Bayley Scales of Infant Development Second Edition (Bayley, 1993), (c) neurologically within "normal" limits (children with abnormal EEGs or controlled seizures were accepted) as determined by a pediatric neurologist (no children were excluded based on this criterion), and (d) a diagnosis of autism by independent child psychiatrists well known for their experience and familiarity with autism. All children also met the criteria for autism based on the Diagnostic and Statistical Manual of Mental DisordersDSM-IV (American Psychiatric Association, 1994) and the Autism Diagnostic Interview-Revised (Lord, Rutter, \& LeCouteur, 1994), both administered by a trained examiner. There were no parental criteria for involvement beyond agreeing to the conditions in the informed consent document, one of which was accepting random assignment to treatment conditions. The parents of all screened children agreed to participate, and none dropped out upon learning of their group assignment, minimizing bias in selection of participants and group composition.

Thirteen children began treatment in 1996, 11 in 1997, and 14 in 1998-1999. The last group had not completed treatment when the data from the first two groups were analyzed, and their data will be reported in a subsequent paper. The 24 children admitted during the first 2 years were 19 boys and 5 girls. One girl was placed in foster care after 1 year of treatment, and the foster parents did not wish to continue treatment for her. Her data were, therefore, excluded from the analysis. The remaining 23 children had completed 4 years of treatment (or had "graduated" earlier) at the time of this report, although 1 child switched to another provider of behavioral treatment after 1 year.

Design

In accordance with the research protocol approved by NIMH, we matched children on pretreatment IQ (Bayley MA divided by CA). They were randomly assigned by a UCLA statistician to the clinic-directed group $(n=13)$, replicating the parameters of the UCLA intensive behavioral treatment (Lovaas, 1987) or to the parent-directed group $(n=10)$, intended to be a less intensive alternative treatment.
All children received treatment based on the UCLA model. Parents in both groups were instructed to attend weekly team meetings and were encouraged to extend the impact of treatment by practicing newly learned material with their child throughout the day. Demographic information as well as hours of treatment and supervision are shown in Table 1. Children averaged 33 to 34 months of age at pretest and began treatment at 35 to 37 months. Children in the clinic-directed

Table 1. Demographic Information and Hours of Service by Group

\begin{tabular}{|c|c|c|}
\hline Descriptor & Clinic-directed & $\begin{array}{l}\text { Parent- } \\
\text { directed }\end{array}$ \\
\hline $\begin{array}{l}\text { Boys, girls } \\
\text { One-parent } \\
\text { families }\end{array}$ & 11,2 & 1 of 10 \\
\hline \multicolumn{3}{|l|}{ Income } \\
\hline $\begin{array}{l}\text { Median (\$) } \\
\text { (Range) }\end{array}$ & $\begin{array}{r}62,000 \\
(35-100+)\end{array}$ & $\begin{array}{r}59,000 \\
(30-100+)\end{array}$ \\
\hline \multicolumn{3}{|l|}{ Education (BA) } \\
\hline $\begin{array}{l}\text { Mothers } \\
\text { Fathers }\end{array}$ & $\begin{array}{r}9 \text { of } 12 \\
10 \text { of } 12\end{array}$ & $\begin{array}{l}9 \text { of } 10 \\
6 \text { of } 9\end{array}$ \\
\hline $\begin{array}{l}\text { Siblings (mean) } \\
\text { No. nonverbal (\%) }\end{array}$ & $\begin{array}{c}2 \\
8 / 13(62)\end{array}$ & $\begin{array}{c}2 \\
2 / 10(20)\end{array}$ \\
\hline \multicolumn{3}{|c|}{ Age (months) (SD) } \\
\hline $\begin{array}{l}\text { Pretest } \\
\text { Treatment } \\
\text { Posttest }\end{array}$ & $\begin{array}{l}33.23(3.89) \\
35.00(4.86) \\
83.23(8.92)\end{array}$ & $\begin{array}{l}34.20(5.06) \\
37.10(5.36) \\
82.50(6.61)\end{array}$ \\
\hline \multicolumn{3}{|l|}{$\begin{array}{c}\text { 1:1 hours per } \\
\text { week }(S D)\end{array}$} \\
\hline Year 1 & $38.60(2.91)$ & $31.67(5.81)$ \\
\hline Year 2 & $36.55(3.83)$ & $30.88(4.04)$ \\
\hline Senior therapist & $\begin{array}{l}\text { 6-10 hrs } \\
\text { per week } \\
\text { 3, 2- to 3-hr } \\
\text { sessions }\end{array}$ & $\begin{array}{l}6 \text { hrs } \\
\text { per month } \\
\text { 1, 3-hr session } \\
\text { per } 2 \text { wks }\end{array}$ \\
\hline Team meetings & $1 \mathrm{hr}$ per week & $\begin{array}{c}1 \mathrm{hr} \text { per } 1 \text { or } \\
2 \text { weeks }\end{array}$ \\
\hline Progress review & $\begin{array}{l}1 \mathrm{hr} \text { per wk } \\
\text { for } 1-2 \\
\text { years then } \\
1 \mathrm{hr} \text { per } 2 \\
\text { months }\end{array}$ & $\begin{array}{l}1 \text { hr every } \\
\text { other } \\
\text { month }\end{array}$ \\
\hline
\end{tabular}

Note. The 1:1 hours for parent-directed children excludes one child who received 14 hours per week.

(C) American Association on Mental Retardation 
group were to receive 40 hours per week of direct treatment. The actual average was 39 during Year 1 and 37 during Year 2, with gradually decreasing hours thereafter as children entered school. Parents in the parent-directed group chose the number of weekly treatment hours provided by therapists. The average was 32 hours during Year 1 and 31 during Year 2, with the exception of one family that chose to have 14 hours both years. Because the parent-directed children as a group received more intensive treatment than was provided in most previous studies, only 6 to 7 hours less than the clinic-directed group, our ability to examine the effect of differences in treatment intensity was limited.

The clinic-directed group received 6 to 10 hours per week of in-home supervision from a senior therapist and weekly consultation by the senior author or clinic supervisor. Parent-directed children received 6 hours per month of in-home supervision from a senior therapist (typically a 3hour session every other week) and consultation every 2 months by the senior author or clinic supervisor.

Direct treatment staff, referred to as therapists, were hired by Wisconsin Early Autism Project staff members for both the clinic- and parent-directed groups. Funding for 35 hours of 1:1 treatment per week was provided through the Wisconsin Medical Assistance program. Treatment hours in excess of 35 were funded through project funds.

\section{Measures}

We used the Bayley Scales of Infant Development, Second Edition, to determine pretreatment IQ. In addition we used the Merrill-Palmer Scale of Mental Tests (Stutsman, 1948), an older test of intelligence recommended for use with nonverbal children (Howlin, 1998), as a measure of nonverbal intelligence but not pre- or posttreatment IQ. We employed the Reynell Developmental Language Scales (Reynell \& Gruber, 1990) to assess language ability, because of its extensive psychometric data for preschool-age children, and the Vineland Adaptive Behavior Scales (Sparrow, Balla, \& Cicchetti, 1984) to measure adaptive functioning. Subscales of the Vineland assess Communication in Daily Life, Daily Living Skills, and Social Skills. Information regarding developmental history (including loss of language and other skills), use of supplemental treatments and pretreatment presence of functional speech was gathered from parent interviews, reports from other professionals, and direct observation.

Follow-up testing was administered annually for 4 years. As children grew older or became too advanced for the norms of pretreatment tests, we used other age-appropriate tests. Cognitive functioning of older children was assessed using Wechsler tests for 20 children-Wechsler Preschool and Primary Scale of Intelligence-RevisedWPPSI (Wechsler, 1989); Wechsler Intelligence Scale for Children-WISC-III (Wechsler, 1991)_ and the Bayley II for 3 children. Although we assessed nonverbal cognitive functioning, it was not used as a measure of posttreatment IQ; we employed the Leiter-R for 11 children (Roid \& Miller, 1995, 1997) and the Merrill-Palmer for 12 children. Language was measured using the Clinical Evaluation of Language Fundamentals, Third Edition-CELF III (Semel, Wiig, \& Secord, 1995) for 11 children and the Reynell for 12 children. We administered the Vineland to all children for assessment of adaptive functioning.

To assess posttreatment social functioning, we readministered the Autism Diagnostic InterviewRevised and used the Personality Inventory for Children (Wirt, Lachar, Klinedinst, \& Seat, 1977), which was completed by parents of all 23 children after 3 years of treatment. After 4 years of treatment, when the children were approximately 7 years old, parents and teachers completed the Child Behavior Checklist (Achenbach, 1991a, 1991b) and Vineland for all 23 children. Bierman and Welsh (1997) noted that "teacher ratings are superior to those of other informants and provide information regarding peer interaction and group acceptance that are closest to those of peers" (p. 348). Information was obtained from teachers on classroom placement (regular, regular with modified curriculum, partial special education [e.g., pullout/resource room or full special education], and supportive/therapeutic services [e.g., classroom aide, speech or occupational therapy]) when the children were 7 years old. We used the Woodcock-Johnson III Tests of Achievement (Woodcock, McGrew, \& Mather, 2001) to measure academic skills of children placed in regular education classes at age 7 .

The second author administered the pretreatment assessment battery prior to children being assigned to treatment groups. She received training in assessment at UCLA and met criterion for satisfactory intertester reliability. One fourth of the children in the current study were tested prior 
to treatment by unaffiliated community psychologists. These children earned a ratio IQ of 50.3 on the Bayley administered by the independent psychologists and 47.3 from the Wisconsin Project evaluator. The mean absolute difference was three points, $r=.83$, indicating absence of bias by the Wisconsin Project evaluator. Children who achieved IQs of 85 or higher at annual follow-up testing were thereafter referred for assessment by psychologists who had extensive experience testing children with autism at hospital-based assessment clinics that were not affiliated with the Wisconsin Project. These psychologists, who were unaware of group assignment or length of time in treatment, used the tests listed above. Follow-up testing of most children whose IQ remained delayed was conducted by the second author to reduce cost.

One experimental assessment procedure, the Early Learning Measure developed at UCLA (Smith, Buch, \& Gamby, 2000) was administered to measure the rate of acquisition of skills during the first several months of treatment. Every 3 weeks for 3 months leading up to the beginning of treatment and for 6 months after treatment started, the same list of 40 items (10 each of verbal imitation, nonverbal imitation, following verbal instructions, and expressive object labeling), which was known only to the experimenter, was presented to the children. Two sets of scores were obtained from the Early Learning Measure. The first was the number of items the child performed correctly prior to the onset of treatment. The second set of scores was the number of weeks required for the child to learn $90 \%$ of the verbal imitation items once treatment had begun, thereby providing a measure of the child's rate of acquisition. This criterion was selected based on earlier research with the Early Learning Measure, which suggested the predictive validity of rapid acquisition of verbal imitation (Lovaas \& Smith, 1988).

\section{Treatment Procedure}

The treatment procedure and curriculum were those initially described by Lovaas (Lovaas et al., 1981), except that no aversives were used, with the addition of procedures supported by subsequent research (e.g., R. Koegel \& Koegel, 1995), which have been widely disseminated (e.g., Maurice, Green, \& Luce, 1996). Positive interactions were built by engaging in favorite activities and responding to the gestures used by each child to indicate desires. Anticipation of success and motivation to attend were increased by employing brief, standard instructions and tasks requiring only visual attending (e.g., matching), using familiar materials (e.g., the child's own ring stacker), prompting success (physically assisting him or her to place a ring on the pole if a demonstration was not sufficient), presenting only two or three trials at a time, and reinforcing each response immediately with powerful reinforcers (e.g., edibles, physical play, or enthusiastic proclamations of success (such as "Fantastic!"). Between these brief (initially 30 seconds long) learning periods, staff members played with the children to keep the process more like play than work, generalize learned material into more natural settings, and continue to build social responsiveness.

Receptive language was generally targeted before expressive language. We used familiar instructions where success was easily prompted, such as "sit down" or "come here." Expressive language began with imitation training, first nonverbal then vocal imitation, beginning with single sounds and gradually progressing to words. Requesting was taught as early as possible, initially using nonverbal strategies if necessary (e.g., gesturing, signing, or the Picture Exchange Communication System-PECS (Bondy \& Frost, 1994), in order to reduce frustration (Carr \& Durand, 1985) and increase the child's frequency of communicative initiations (Hart \& Risley, 1975). Children who showed more modest gains in treatment, referred to as visual learners by the UCLA group, denoting difficulty in processing language, took longer to acquire verbal imitation and language.

Having learned many labels, children were taught more complex concepts and skills, such as categorization and speaking in full sentences. Social interaction and cooperative play were taught as part of the in-home program, expanding from playing with staff, to playing with siblings, and then peers for up to 2 hours per day (this was more successful with the subgroup of rapidly learning children). As the children acquired social skills, they began mainstream (as opposed to special education) preschool, usually for just 1 or 2 half-days (2.5 hours each) per week. A trained shadow (one of the home treatment team members) initially accompanied the child to assist with attending to the teacher's instructions, joining others on the playground, and noting social errors to be addressed in 1:1 sessions at home.

Those children who progressed at a rapid pace 
were taught the beginnings of inferential thought (e.g., "Why does he feel sad?"). Social and conversation skills, such as topic maintenance and asking appropriate questions, were taught using role-playing (e.g., Jahr, Eldevik, \& Eikeseth, 2000), video modeling (Charlop \& Milstein, 1989), social stories (Gray, 1994), straightforward discussion of social rules and etiquette, and in-vivo prompting.

Academic skills were also targeted, raising the level of proficiency of rapidly learning children to first grade levels. Common classroom rules and school "survival skills" (e.g., responding to group instructions and raising one's hand to be called on-Dawson \& Osterling, 1997) were taught through "mock school" exercises with several peers at home.

Staff training. Therapists were at least 18 years old, had completed a minimum of 1 year of college, and were screened for prior police contacts. Therapists received 30 hours of training, which included a minimum of 10 hours of one-to-one training and feedback while working with their assigned child. Each therapist worked at least 6 hours per week (usually three 2-hour shifts) and attended weekly or bi-weekly team meetings. Senior therapists had at least a 4-year college degree and experience consisting of 1 year as a therapist with at least two children, followed by an intensive 16-week internship program modeled after that at UCLA, for a total of 2,000 hours.

Treatment fidelity. Senior therapists and clinicdirected therapists were required to meet quality control criteria set at UCLA. This involved passing two tests. The first was a written test designed to assess knowledge of basic behavioral principles and treatment procedures described in The Me Book (Lovaas et al., 1981). Second, they were required to pass a videotaped review of their work (conducted by Tristram Smith, research director of the Multi-Site Project, who used the protocol described by R. Koegel, Russo, and Rincover, 1977). All senior therapists also received weekly supervision by the senior author.

Progress reviews, which the child, parents, and senior therapist attended, were held weekly for clinic-directed children and every 2 months for parent-directed children. At these reviews, the senior author or the UCLA-trained clinic supervisor observed the child's performance and recommended appropriate changes in the program. Both the senior author and clinic supervisor had met the UCLA criteria for Level Two Therapist, denoting sufficient experience and expertise in program implementation to work independent of supervision. The senior author had directed a behaviorally oriented inpatient unit for children with autism for 14 years and had trained at UCLA for 6 months. The clinic supervisor had a BA in psychology, 1 year of experience as a therapist, 2 years of full-time experience as a senior therapist, and had completed a 9-month internship at UCLA.

\section{Data Analysis}

Data analysis was carried out by a fourth year graduate student from the University of Wisconsin Department of Statistics, with consultation from a university research psychologist. We conducted an ANOVA with a least squares solution for unequal group size, used to examine treatment effects. To compare the clinic-directed and parentdirected groups, we used $2 \times 2$ ANOVAS (ClinicDirected vs. Parent-Directed $\times$ Pre- vs. Posttest scores as repeated measures). An initial examination of pre-post IQ data showed that the distribution of scores was bimodal. As can be seen in Figure 1, children showed either rapid progress or more moderate progress, with no overlap between outcome distributions. This is consistent with earlier research (Birnbrauer \& Leach, 1993; Howard, Sparkman, Cohen, Green, \& Stanislaw, 2005; O. I. Lovaas, personal communication, August 27, 2003). Consequently, changes in scores for rapid learners and moderate learners were analyzed separately.

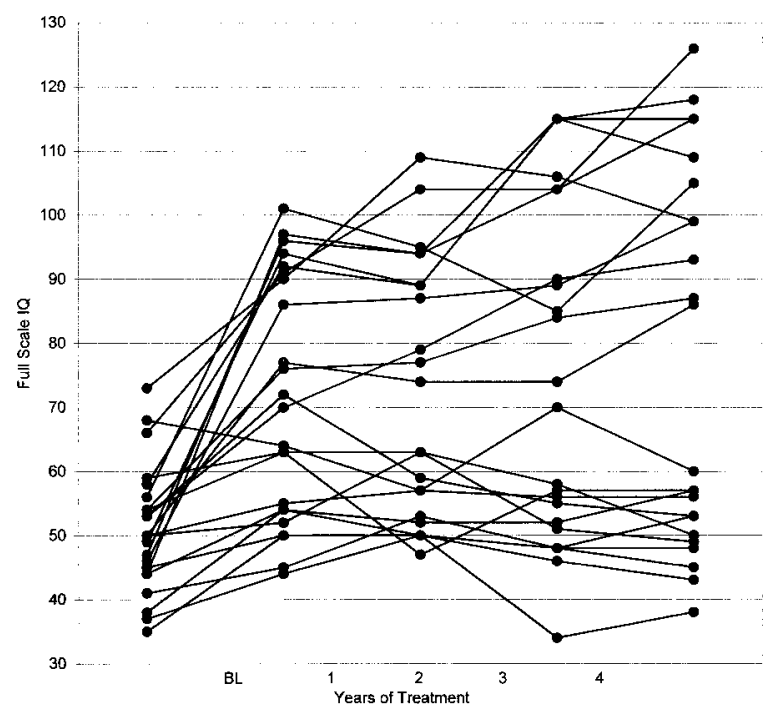

Figure 1. Changes in Full Scale IQ during 4 years of behavioral treatment. 
In examining pretreatment scores of children who would later be identified as rapid learners, we found that those in the clinic-directed group had higher mean IQ (60.40, standard deviation [SD] $=8.31$ compared to those in the parent-directed group (51.00, $S D=7.02), t(9)=1.84, p<.05$ (one tailed), Vineland scores (clinic-directed $=64.8$, $S D=2.32$; parent-directed $=59.83, S D=3.34)$, $t(9)=2.31, p<.05$ (one tailed), and Verbal Imitation (clinic-directed $=3.88$; parent-directed $=$ 1.67), $W(4,6)=31, p=.03$ (Wilcoxon test). Because these pretreatment differences would interfere with clear interpretation of posttreatment differences between subgroups (e.g., clinic-directed vs. parent-directed rapid learners), these comparisons were omitted. We used linear and logistic regression (best subset selection approach-Hosmer, Jovanovic, \& Lemeshow, 1989) to develop prediction models using pretreatment measures as predictors of 3-year outcome.

\section{Results}

The average Full Scale IQ for all 23 children increased from 51 to 76, a 25-point increase. Eight of the children achieved IQs of 85 or higher after 1 year of treatment (5 clinic-directed and 3 parentdirected), and 3 more reached this level after 3 to 4 years (3 parent-directed) for a total of 11 , or $48 \%$, of the 23 children. Children with higher pretreatment IQs were more likely to reach 4-year IQs in the average range $75 \%$ of children with IQs between 55 and 64 versus 17\%, 1 of 6 children with IQs between 35 and 44).

As shown in Table 2, there were no significant differences between groups at pre- or posttest. Combining children in both groups, we found that pretest to posttest gains were significant for Full Scale IQ, $F(1,21)=18.77, p<.01$, Verbal IQ, $F(1,18)=13.39, p<.01$, Performance IQ, $F(1,18)=46.79, p<.01$, receptive language, $F(1$, $21)=9.18, p<.01$, Vineland Communication, $F(1,21)=7.57, p<.05$, Vineland Socialization, $F(1,21)=10.30, p<.01$, Autism Diagnostic Interview-Revised Social Skills, $F(1,18)=19.15$, $p$ $<.01$, and Communication, $F(1,18)=41.19, p$ $<.01$.

\section{Rapid and Moderate Learners}

A group of rapid learners showed much larger improvements than did moderate learners (analogous to the terms best outcome and non-best outcome used in UCLA reports). Figure 1 shows Full
Scale IQs prior to treatment and over the next 4 years for all 23 children. Eleven of them (5 clinicdirected and 6 parent-directed) showed a large increase in IQ, from a mean of 55 prior to treatment to 104 after 4 years. These rapid learners represented $48 \%$ of all 23 children. The IQ of the remaining 12 children (8 clinic-directed and 4 parent-directed) did not show a significant increase, consistent with earlier UCLA reports (e.g., Smith et al., 2000).

Pre- and posttreatment scores of rapid and moderate learners are shown in Table 3. Rapid learners showed significant gains in all areas measured (i.e., Full Scale IQ, $F(1,21)=143.19, p<$ .01 , Verbal IQ, $F(1,18)=70.76, p<.01$, Performance IQ, $F(1,18)=165.27, p<.01$, Nonverbal IQ, $F(1,19)=16.69, p<.01$, Receptive Language, $F(1,20)=217.76, p<.01$, Expressive Language, $F(1,20)=77.76, p<.01$, and all Vineland subscales: Communication, $F(1,21)=147.07, p$ $<.01$, Daily Living Skills $(F(1,21)=20.50, \mathrm{p}<$ $.01)$, Socialization, $F(1,21)=42.89, p<.01$, and Applied Behavior Composite, $F(1,21)=54.17, p$ $<.01)$. However, the rate of increase over time, skill areas, and children was not uniform. As can be seen in Figure 2, during the first year, Performance IQ of rapid learners rose to the average range (a 40-point increase, WPPSI-R), whereas Verbal IQ and Vineland Socialization scores rose to around 80 (a 25-point increase) and language scores (Reynell and Clinical Evaluation of Language Fundamentals) rose only to the 60s. Changes during the second year of treatment were comparatively modest, perhaps reflecting the effect of having acquired speech during the first year but still lacking more complex language. The rate of improvement increased again during the third and fourth years, and all scores increased to the average range.

The gradual decrease in the slope of the graphs in Years 3 and 4 is largely an artifact of increasing age and does not reflect a decrease in rate of MA growth, which, except for the large increase during Year 1, averaged 18 months per year throughout the study. This rate of growth in skills is necessary for children with pretreatment scores below 60 to "catch up" to peers. Although some writers have noted a rate of growth among treated children of 10 to 12 months per year, this is not enough for them to reach scores in the average range within just a few years (Howard et al., 2005), and the longer that children are delayed, the more skills they must learn to catch up.
(C) American Association on Mental Retardation 
Table 2. Pretreatment and Outcome Scores of Clinic- (CD) and Parent-Directed (PD) Groups

\begin{tabular}{|c|c|c|c|c|c|}
\hline \multirow{2}{*}{$\begin{array}{l}\text { Measure/ } \\
\text { Group }\end{array}$} & \multicolumn{2}{|c|}{ Pretreatment } & \multicolumn{2}{|c|}{ Posttreatment } & \multirow{2}{*}{$\begin{array}{l}\text { ANOVA, combined } \\
\text { groups, pre- vs. } \\
\text { posttreatment ( } d f)\end{array}$} \\
\hline & Mean & $S D$ & Mean & $S D$ & \\
\hline \multicolumn{6}{|c|}{ Full Scale IQ } \\
\hline $\begin{array}{l}C D \\
P D\end{array}$ & $\begin{array}{l}50.85 \\
52.10\end{array}$ & $\begin{array}{r}10.57 \\
8.98\end{array}$ & $\begin{array}{l}73.08 \\
79.60\end{array}$ & $\begin{array}{l}33.08 \\
21.80\end{array}$ & $18.77(1,21) * *$ \\
\hline \multicolumn{6}{|l|}{ Verbal IQ } \\
\hline $\begin{array}{l}C D \\
P D\end{array}$ & - & - & $\begin{array}{l}78.00 \\
76.30\end{array}$ & $\begin{array}{l}33.48 \\
26.66\end{array}$ & $13.39(1,18)$ ** \\
\hline \multicolumn{6}{|c|}{ Perform IQ } \\
\hline $\begin{array}{l}C D \\
P D\end{array}$ & - & - & $\begin{array}{l}84.90 \\
90.70\end{array}$ & $\begin{array}{l}25.86 \\
20.72\end{array}$ & $46.79(1,18)$ ** \\
\hline \multicolumn{6}{|c|}{ Nonverbal IQ } \\
\hline $\begin{array}{l}C D \\
P D\end{array}$ & $\begin{array}{l}70.58 \\
82.67\end{array}$ & $\begin{array}{l}16.54 \\
14.94\end{array}$ & $\begin{array}{l}77.58 \\
89.44\end{array}$ & $\begin{array}{l}25.24 \\
18.35\end{array}$ & $2.07(1,21)$ \\
\hline \multicolumn{6}{|c|}{ Rec Language } \\
\hline $\begin{array}{l}C D \\
P D\end{array}$ & $\begin{array}{l}38.85 \\
38.78\end{array}$ & $\begin{array}{l}6.09 \\
6.44\end{array}$ & $\begin{array}{l}55.85 \\
65.78\end{array}$ & $\begin{array}{l}36.23 \\
25.81\end{array}$ & $9.18(1,21)^{* *}$ \\
\hline \multicolumn{6}{|c|}{ Exp Language } \\
\hline $\begin{array}{l}C D \\
P D\end{array}$ & $\begin{array}{l}47.92 \\
48.44\end{array}$ & $\begin{array}{l}6.17 \\
6.96\end{array}$ & $\begin{array}{l}53.38 \\
59.22\end{array}$ & $\begin{array}{l}31.91 \\
25.13\end{array}$ & $1.30(1,20)$ \\
\hline \multicolumn{6}{|l|}{$\begin{array}{l}\text { Vineland } \\
\text { Com }\end{array}$} \\
\hline $\begin{array}{l}C D \\
P D\end{array}$ & $\begin{array}{l}57.46 \\
63.20\end{array}$ & $\begin{array}{l}4.97 \\
5.58\end{array}$ & $\begin{array}{l}73.69 \\
81.40\end{array}$ & $\begin{array}{l}32.32 \\
24.33\end{array}$ & $7.57(1,21)^{*}$ \\
\hline \multicolumn{6}{|l|}{ DLS } \\
\hline $\begin{array}{l}C D \\
P D\end{array}$ & $\begin{array}{l}63.92 \\
64.20\end{array}$ & $\begin{array}{l}5.53 \\
3.68\end{array}$ & $\begin{array}{l}66.23 \\
64.20\end{array}$ & $\begin{array}{l}25.95 \\
12.42\end{array}$ & $.11(1,21)$ \\
\hline \multicolumn{6}{|l|}{ Soc } \\
\hline $\begin{array}{l}C D \\
\text { PD }\end{array}$ & $\begin{array}{l}58.38 \\
60.30\end{array}$ & $\begin{array}{l}6.17 \\
5.76\end{array}$ & $\begin{array}{l}73.92 \\
68.90\end{array}$ & $\begin{array}{l}23.49 \\
10.11\end{array}$ & $10.30(1,21) * *$ \\
\hline \multicolumn{6}{|l|}{$A B C^{b}$} \\
\hline $\begin{array}{l}C D \\
P D\end{array}$ & $\begin{array}{l}59.54 \\
60.90\end{array}$ & $\begin{array}{l}5.31 \\
5.94\end{array}$ & $\begin{array}{l}69.00 \\
66.70\end{array}$ & $\begin{array}{l}28.04 \\
14.68\end{array}$ & $2.81(1,21)$ \\
\hline \multicolumn{6}{|l|}{$\begin{array}{l}\text { ADI-Rc } \\
\text { Social }\end{array}$} \\
\hline $\begin{array}{l}C D \\
P D\end{array}$ & $\begin{array}{l}17.54 \\
18.90\end{array}$ & $\begin{array}{l}3.73 \\
1.14\end{array}$ & $\begin{array}{l}12.33 \\
13.10\end{array}$ & $\begin{array}{r}10.58 \\
9.42\end{array}$ & $19.15(1,18) * *$ \\
\hline \multicolumn{6}{|l|}{ Com } \\
\hline $\begin{array}{l}C D \\
P D\end{array}$ & $\begin{array}{l}12.85 \\
12.90\end{array}$ & $\begin{array}{l}2.44 \\
1.22\end{array}$ & $\begin{array}{l}8.08 \\
8.80\end{array}$ & $\begin{array}{l}6.91 \\
7.43\end{array}$ & $41.19(1,18)$ ** \\
\hline \multicolumn{6}{|l|}{ Ritual } \\
\hline $\begin{array}{l}C D \\
P D\end{array}$ & $\begin{array}{l}5.38 \\
6.40\end{array}$ & $\begin{array}{l}1.69 \\
1.11\end{array}$ & $\begin{array}{l}5.08 \\
5.60\end{array}$ & $\begin{array}{l}3.75 \\
3.50\end{array}$ & $1.72(1,18)$ \\
\hline
\end{tabular}

Note. CD $n=13$; PD $n=10$ except for Verbal IQ and Performance IQ, where $n$ was 10 for both groups because 3 CD children had only Bayley tests. Neither the main effect of groups (CD vs. PD) nor the interaction of groups by time was significant for any variable. Full scale IQs at pretreatment are Bayley scores.

${ }^{a}$ Daily living skills. ${ }^{b}$ Adaptive Behavior Composite. ${ }^{c}$ Autism Diagnostic Interview-Revised.

${ }^{*} p<.05 . * * p<.01$. 
Table 3. Pretreatment and Outcome Scores of Rapid (R) and Moderate (M) Learners

\begin{tabular}{|c|c|c|c|c|c|}
\hline \multirow{2}{*}{$\begin{array}{l}\text { Measure/ } \\
\text { Group }\end{array}$} & \multicolumn{2}{|c|}{ Pretreatment } & \multicolumn{2}{|c|}{ Posttreatment } & \multirow{2}{*}{$\begin{array}{l}\text { ANOVA Pre-Post } \\
\text { comparisons }\end{array}$} \\
\hline & Mean & $S D$ & Mean & $S D$ & \\
\hline \multicolumn{6}{|c|}{ Full Scale IQ } \\
\hline $\mathrm{R}$ & 55.27 & 8.96 & 103.73 & 13.35 & $143.19(1,21) * *$ \\
\hline $\mathrm{M}$ & 47.83 & 9.37 & 50.42 & 6.98 & $0.45(1,21)$ \\
\hline \multicolumn{6}{|l|}{ Verbal IQ } \\
\hline $\mathrm{R}$ & - & - & 101.45 & 18.72 & $70.76(1,18) * *$ \\
\hline $\mathrm{M}$ & - & - & 47.44 & 2.06 & $.02(1,18)$ \\
\hline \multicolumn{6}{|c|}{ Perform IQ } \\
\hline $\mathrm{R}$ & - & - & 107.55 & 9.44 & $165.27(1,18) * *$ \\
\hline $\mathrm{M}$ & - & - & 63.67 & 8.43 & $11.81(1,18)^{* *}$ \\
\hline \multicolumn{6}{|c|}{ Nonverbal IQ } \\
\hline $\mathrm{R}$ & 83.56 & 14.84 & 108.78 & 10.96 & $16.69(1,19) * *$ \\
\hline $\mathrm{M}$ & 69.83 & 15.93 & 67.70 & 12.35 & $0.19(1,19)$ \\
\hline \multicolumn{6}{|c|}{ Rec Language } \\
\hline $\mathrm{R}$ & 39.30 & 6.91 & 93.60 & 12.64 & $217.76(1,20) * *$ \\
\hline $\mathrm{M}$ & 38.42 & 5.59 & 31.83 & 9.87 & $3.84(1,20)$ \\
\hline \multicolumn{6}{|c|}{ Exp Language } \\
\hline $\mathrm{R}$ & 49.90 & 7.75 & 85.70 & 15.07 & $77.76(1,20) * *$ \\
\hline $\mathrm{M}$ & 47.50 & 6.54 & 30.83 & 5.89 & $20.24(1,20)$ ** \\
\hline \multirow{2}{*}{\multicolumn{6}{|c|}{$\begin{array}{l}\text { Vineland } \\
\text { Com }\end{array}$}} \\
\hline & & & & & \\
\hline $\mathrm{R}$ & 60.82 & 4.02 & 105.09 & 12.83 & $147.07(1,21) * *$ \\
\hline$M$ & 59.17 & 7.22 & 51.33 & 10.94 & $5.07(1,21)^{*}$ \\
\hline \multicolumn{6}{|l|}{ DLSa } \\
\hline $\mathrm{R}$ & 66.45 & 4.25 & 82.27 & 16.34 & $20.50(1,21) * *$ \\
\hline M & 61.83 & 4.20 & 49.83 & 10.61 & $12.87(1,21) * *$ \\
\hline \multicolumn{6}{|l|}{ Soc } \\
\hline $\mathrm{R}$ & 61.55 & 6.58 & 87.73 & 14.94 & $42.89(1,21) * *$ \\
\hline $\mathrm{M}$ & 57.08 & 4.63 & 57.08 & 6.40 & $0.00(1,21)$ \\
\hline \multicolumn{6}{|l|}{$A B C^{b}$} \\
\hline $\mathrm{R}$ & 61.73 & 4.59 & 88.64 & 15.68 & $54.17(1,21) * *$ \\
\hline M & 58.67 & 6.09 & 49.08 & 7.76 & $7.51(1,21) *$ \\
\hline \multicolumn{6}{|l|}{$\begin{array}{l}\text { ADI-Rc } \\
\text { Social }\end{array}$} \\
\hline $\mathrm{R}$ & 16.45 & 3.26 & 4.18 & 4.37 & $46.89(1,21)^{* *}$ \\
\hline M & 19.67 & 1.55 & 21.18 & 6.28 & $0.43(1,21)$ \\
\hline \multicolumn{6}{|l|}{ Com } \\
\hline $\mathrm{R}$ & 11.00 & 3.54 & 2.00 & 2.73 & $52.04(1,21) * *$ \\
\hline M & 13.75 & 0.60 & 14.81 & 3.59 & $1.26(1,21)$ \\
\hline \multicolumn{6}{|l|}{ Ritual } \\
\hline $\mathrm{R}$ & 5.91 & 1.62 & 2.73 & 2.67 & $16.46(1,21)^{* *}$ \\
\hline$M$ & 5.92 & 1.44 & 7.91 & 2.47 & $4.87(1,21)^{*}$ \\
\hline
\end{tabular}

Note. $\mathrm{R} n=11 ; \mathrm{M} n=12$. Posttreatment language scores for moderate learners are Reynell ratio scores (AE/CA), which are about 10 points lower than standard scores. Effect size expressed as proportion of variance was .88 for Full Scale IQ, .90 for receptive language, .84 for expressive language, and .73 for Vineland ABC, all quite large (Cohen, 1988). Full Scale IQs at pretreatment are Bayley scores.

${ }^{a}$ Daily living skills. ${ }^{\mathrm{b}}$ Adaptive Behavior Composite. ${ }^{\mathrm{c} A u t i s m ~ D i a g n o s t i c ~ I n t e r v i e w-R e v i s e d . ~}$

${ }^{*} p<.05 . * * p<.01$. 


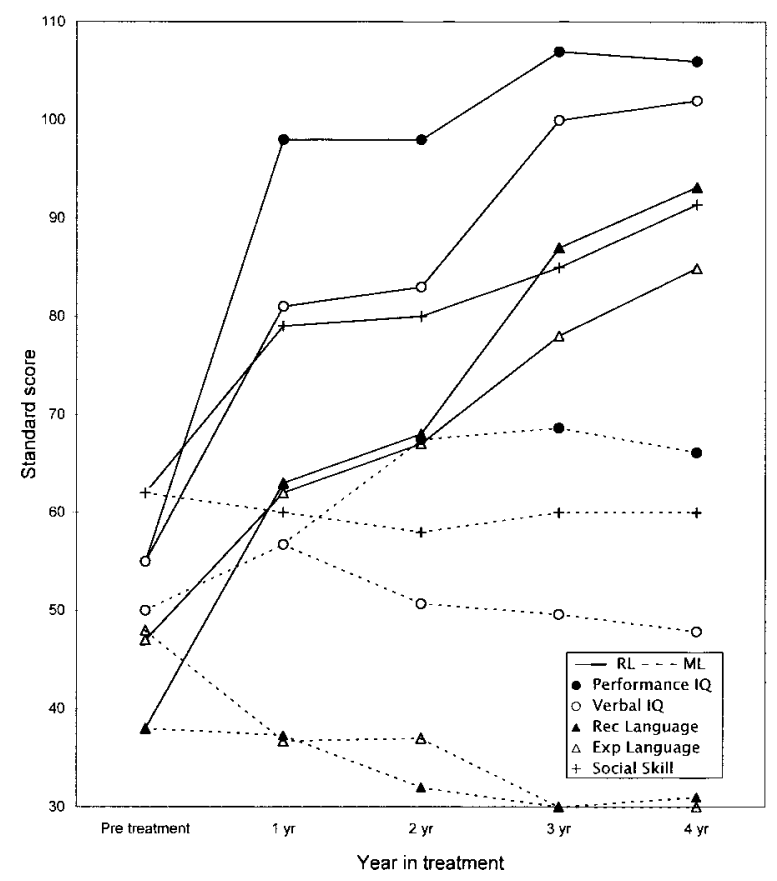

Figure 2. Mean IQ, language, and socialization scores during treatment for rapid (RL) and moderate (ML) learners. Initial IQ and language scores are ratio scores as are all language scores of moderate learners.

Most parents waited until their children were 6 years old to enter kindergarten, per our recommendation, in order to allow them more time to acquire social interaction skills. At an average age of 7.67, the 11 rapidly learning children were succeeding in regular first or second grade classes following the regular curriculum. On the Woodcock Johnson III Tests of Achievement, Oral Expression averaged $102(S D=11.9,1$ scored below 85$)$, Listening Comprehension averaged $101(S D=$ 15.27, 2 scored below 85), Broad Reading averaged $105(S D=11.9$, all scored over 85), Broad Math averaged $104(S D=18.4$, one scored below 85), Spelling averaged $112(S D=18.83$, all scored over 85) and general Academic Knowledge averaged 98 ( $S D=18.1,2$ scored below 85). Three children had aides because of inattentiveness and 3 received speech therapy, although all spoke fluently.

The 12 moderate learners showed a significant improvement in Performance IQ, $F(1,18)=$ $11.81, p<.01$, as shown in Table 3 , but the posttreatment mean score (63.67) was over two SDs below the average range. Although these children did not "catch up" to peers, they did show in- creases in developmental age equivalents. Cognitive skills increased from 16 to 44 months; adaptive skills, from 16 to 37 months; language skills, from less than 12 months to 27 months; and social skills, from 10 to 31 months. At the end of the study, these children were continuing to gain skills at a rate of 3.4 to 4.3 months per year in expressive language and social skills, respectively. All but 2 of them acquired speech, allowing them to communicate basic needs while also reducing frustration. Two thirds learned to read simple stories (e.g., first grade level words with two sentences per page). Most acquired the ability to relate to others and to play with peers. Four of the children were in regular classes with an aide, but all had a modified curriculum. Six children had a mixture of some time in regular class and some time in special education, and 2 were in full-time special education classes (one for students with cognitive disabilities and the other for those with emotional disturbances).

\section{Assessment of Residual Symptoms in Rapidly Learning Children}

Parents completed the Personality Inventory for Children for all 23 children. As shown in Table 4, rapidly learning children as a group scored in the average range on all factor scales, although 2 scored in the clinically significant range on Factor III (they tended to worry). Moderate learners were rated as having more tantrums (Factor I), more difficulty interacting with others (Factor II), and more learning problems (Factor IV).

Parents and teachers completed the Child Behavior Checklist for all 23 children. Results were analyzed using $2 \times 2$ ANOVAS (Rapid Learners vs. Moderate Learners $\times$ Parent vs. Teacher as repeated measures). As shown in Tables 4 and 5, rapid learners as a group scored in the nonclinically significant range on all scales, although they did score less normally than did moderate learners on Scale 3 (they worried more). Moderate learners were rated as less interactive (Scale 1), more preoccupied (Scale 5), less attentive (Scale 6), and more easily frustrated (Scale 8).

The differences in Child Behavior Checklist ratings between parents and teachers were small, reaching significance on two scales (1 and 8). However, these results largely reflected differences within the average range. Parents did not rate any children in the clinically significant range on either scale, and teachers rated only 2 children on 
Table 4. Mean Scores of Rapid and Moderate Learners on Posttreatment Only Tests of Residual Symptoms: Parent Ratings

\begin{tabular}{|c|c|c|c|c|c|c|c|c|c|c|}
\hline \multirow[b]{2}{*}{ Learner } & \multicolumn{4}{|c|}{ PIC factor } & \multicolumn{6}{|c|}{ Child Behavior Checklist ${ }^{\mathrm{b}}$ scale } \\
\hline & 1 & II & III & IV & 1 & 3 & 4 & 5 & 6 & 8 \\
\hline \multicolumn{11}{|l|}{ Rapid (R) } \\
\hline $\begin{array}{l}(n=11) \\
(S D)\end{array}$ & $\begin{array}{l}53.45 \\
(9.38)\end{array}$ & $\begin{array}{l}62.36 \\
(8.34)\end{array}$ & $\begin{array}{c}55.27 \\
(13.90)\end{array}$ & $\begin{array}{c}64.18 \\
(13.65)\end{array}$ & $\begin{array}{l}59.09 \\
(6.26)\end{array}$ & $\begin{array}{l}55.40 \\
(6.14)\end{array}$ & $\begin{array}{c}57.82 \\
(7.49)\end{array}$ & $\begin{array}{l}65.64 \\
(9.87)\end{array}$ & $\begin{array}{l}62.64 \\
(9.12)\end{array}$ & $\begin{array}{l}52.91 \\
(4.98)\end{array}$ \\
\hline \multicolumn{11}{|c|}{ Moderate (M) } \\
\hline $\begin{array}{l}(n=12) \\
(S D)\end{array}$ & $\begin{array}{c}66.83 \\
(12.93)\end{array}$ & $\begin{array}{l}79.25 \\
(9.42)\end{array}$ & $\begin{array}{l}49.73 \\
(8.77)\end{array}$ & $\begin{array}{c}97.55 \\
(18.77)\end{array}$ & $\begin{array}{l}58.83 \\
(6.27)\end{array}$ & $\begin{array}{l}51.75 \\
(3.06)\end{array}$ & $\begin{array}{l}61.92 \\
(7.35)\end{array}$ & $\begin{array}{l}70.42 \\
(7.92)\end{array}$ & $\begin{array}{l}67.67 \\
(8.17)\end{array}$ & $\begin{array}{l}53.33 \\
(4.62)\end{array}$ \\
\hline $\mathrm{R}$ vs. $\mathrm{M}^{\mathrm{c}}$ & $3.43 * *$ & $4.86 * *$ & 1.06 & $5.13 * *$ & 0.01 & $1.80 *$ & 1.61 & 1.64 & $1.73 *$ & 0.08 \\
\hline
\end{tabular}

aPersonality Inventory for Children and Child Behavior Checklist scores $\geq 70$ are clinically significant and scores $\geq 67$ are borderline. Scores below those levels are not reliably different from "normal" (Achenbach, 1991b; Lacher, 1982). Factor I = Undisciplined/Poor Self Control, II = Social Incompetence, III = Internalizing/Somatic Symptoms, IV = Cognitive Development. ' ${ }^{\text {S }}$ cale I $=$ Withdrawn, 3 = Anxious/Depressed, $4=$ Social Problems, $5=$ Thought Problems, $6=$ Attention Problems, $8=$ Aggression. $^{c} t$ tests are one-tailed, with a $d f$ of 19.

$* p<.05 . * p<.01$.

Scale 1 (both moderate learners) and 3 on Scale 8 in the significant range (1 rapid and 2 moderate learners).

Whereas checklists such as the Personality Inventory for Children and the Child Behavior Checklist can be used to assess the presence of problems, the Classroom Edition of the Vineland is used to assess the presence of skills (e.g., "initiates conversation," "responds to hints or indirect cues in conversation"). Teachers completed this measure for all 23 children except the 2 who were among the highest functioning. As shown in Table 5, teacher ratings of Communication and Socialization for the remaining 9 rapid learners were in the average range. Moderate learners were rated as having deficiencies in both areas.
We examined changes in behavior related to diagnosis by comparing the Autism Diagnostic Interview-Revised administered prior to and after 3 years of treatment using $2 \times 2$ ANOVAS (Rapid Learners vs. Moderate Learners $\times$ Pretreatment vs. Posttreatment as repeated measures). As shown in Table 3, rapid learners as a group showed significant improvements on all three Autism Diagnostic Interview scales: Communication, $F(1,21)=$ 52.04, $p<.01$, Reciprocal Interaction, $F(1,21)=$ $46.89, p<.01$, and stereotyped behaviors, $F(1,21)$ $=16.46, p<.01$. Eight of 11 rapid learners scored in the nonautistic range in all three areas, and many had their diagnoses removed by the referring child psychiatrists. Of the rapid learners who had remaining problems, 1 still had some lan-

Table 5. Mean Scores of Rapid and Moderate Learners on Posttreatment Only Tests of Residual Symptoms: Teacher Ratings

\begin{tabular}{lcccccccccc}
\hline & \multicolumn{2}{c}{ Vineland } & & \multicolumn{5}{c}{ Child Behavior Checklist scales } \\
\cline { 2 - 6 } \cline { 6 - 9 } Learners & Comm. & Social & & 1 & 3 & 4 & 5 & 6 & 8 \\
\hline Rapid (R) & 94.44 & 89.89 & & 57.00 & 55.90 & 56.73 & 65.55 & 59.36 & 57.60 \\
$n=11(S D)$ & $(13.97)$ & $(18.36)$ & & $(7.34)$ & $(6.93)$ & $(6.30)$ & $(11.37)$ & $(12.33)$ & $(6.11)$ \\
Moderate (M) & 58.58 & 61.58 & & 64.33 & 55.17 & 58.00 & 72.58 & 63.25 & 61.25 \\
$n=12(S D)$ & $(7.90)$ & $(6.02)$ & & $(6.03)$ & $(6.56)$ & $(5.57)$ & $(7.06)$ & $(7.94)$ & $(7.45)$ \\
R vs. M & $6.84^{* *}$ & $4.60^{* *}$ & & $2.93^{* *}$ & 0.36 & 0.37 & $2.41^{*}$ & 1.33 & $2.86^{* *}$ \\
\hline
\end{tabular}

"Child Behavior Checklist scores $\geq 67$ are borderline. Scores below these levels are not reliably different from "normal" (Achenbach, 1991b; Lacher, 1982). $t$ tests are one-tailed. Scale $1=$ Withdrawn, $3=$ Anxious/Depressed, $4=$ Social Problems, $5=$ Thought Problems, $6=$ Attention Problems, $8=$ Aggression. ${ }^{\mathrm{b}} t$ tests are one-tailed, with a $d f$ of 19. ${ }^{*} p<.05$. ${ }^{* *} p<.01$. 
Table 6. Combined Parents' and Teachers' Ratings of Residual Symptoms of Rapid Learners

\begin{tabular}{ccccccc}
\hline & $\begin{array}{c}\text { Social Skills } \\
\text { VABSb } \\
\text { Com, Soc }\end{array}$ & $\begin{array}{c}\text { Isolates } \\
\text { PICc 1\&2 }\end{array}$ & $\begin{array}{c}\text { Not liked } \\
\text { CBC 1,4 }\end{array}$ & $\begin{array}{c}\text { Anxious } \\
\text { CBC 3, PIC 3 }\end{array}$ & $\begin{array}{c}\text { Inattntn } \\
\text { CBC 5,6 }\end{array}$ & Moody CBC 8 \\
\hline Child & CD & & & & & \\
1 & 104 & 50 & 50 & 47.7 & 50 & 50 \\
2 & 115.5 & 50 & 50 & 48.3 & 50 & 50 \\
3 & 115 & 51 & 50 & 51.3 & 55 & 50 \\
4 & 101.3 & 57.5 & 68.3 & 52 & 79.5 & 65.5 \\
5 & 95.5 & 51 & 56.3 & 60 & 62.5 & 53 \\
PD & & & & & & \\
1 & 107.5 & 59 & 55.3 & 68.3 & 54 & 54.5 \\
2 & 79.5 & 54.5 & 57.3 & 46.3 & 67.5 & 54.5 \\
3 & 77.5 & 67.5 & 60 & 51.3 & 64.8 & 61.5 \\
4 & 77.5 & 69 & 63.8 & 63.7 & 70.8 & 58 \\
5 & 86.5 & 67 & 61.3 & 67.0 & 67.8 & 51 \\
6 & 99.5 & 64 & 62.3 & 51.3 & 65 & 55.5 \\
\hline
\end{tabular}

${ }^{\mathrm{a}} \mathrm{CD}=$ clinic directed, $\mathrm{PD}=$ parent directed. ${ }^{\mathrm{b}}$ Vineland Adaptive behavior Scales (VABS) scores below 85 are moderately low and 116-130, moderately high. cPersonality Inventory for Children (PIC) and Child Behavior Checklist (CBC) scores $\geq 70$ are clinically significant; and $\geq 67$, borderline; below these levels, are not reliably different from "normal" (Achenbach, 1991b; Lacher, 1982).

guage delays, 1 was rigid in play, and 1 was elevated in all three areas. The latter child had received treatment from a non-UCLA affiliated provider after the first year.

Combined measures of residual symptoms are shown in Table 6. Eight of 11 rapid learners showed increases in social skills to the adequate range (above 85 ), although 3 had some borderline problems, including 1 who had significant problems with Preoccupation/Inattention. The remaining 3 rapid learners showed moderately low social skills (below 85), and 2 had problems with Preoccupation/Inattention, one of which was clinically significant. All 3 of these latter children were in the parent-directed group and took longer than 2 years to achieve IQ in the average range. These results are similar to those described in UCLA reports, where 3 of 8 best outcome children scored below 85 on Vineland Communication, 3 were elevated on the Vineland Maladaptive Behavior scale, and 5 had at least one significant elevation on the Personality Inventory for Children. In interpreting these results, McEachin et al. (1993) noted that 3 of their nonclinical children also had significant Personality Inventory elevations.

\section{Predicting Outcome}

Early learning measure. Performance of rapid and moderate learners on each of the four sub- scales of the Early Learning Measure is shown in Figure 3. As can be seen, the difference in their rates of learning was evident early in treatment. Thirteen of 23 children passed the Early Learning Measure (90\% correct on verbal imitation). All 11 who later achieved scores in the average range passed by 16 weeks of treatment ( 9 children) or before reaching 42 months of age ( 2 children).

Pretreatment variables. Table 7 shows correlations between pretreatment variables and three outcome variables following 3 years of treatment: (a) Full Scale IQ; (b) Language, defined as the mean of three measures-Vineland Communication scores from parents and teachers representing language usage at home and school and language scores from the Reynell or Clinical Evaluation of Language Fundamentals; (c) Social Skills, defined as the mean of three measures-Vineland Socialization scores from parents and teachers and Factor II (Social Incompetence) from the Personality Inventory for Children.

The ability to imitate on the Early Learning Measure was highly correlated with outcome in all three areas. Seven children were able to imitate 3 of 20 sounds prior to treatment (mean total sounds imitated during the first three Early Learning Measures was 2.43, range $=0$ to $15, S D=$ 4.04), and all went on to achieve IQs in the average range. 

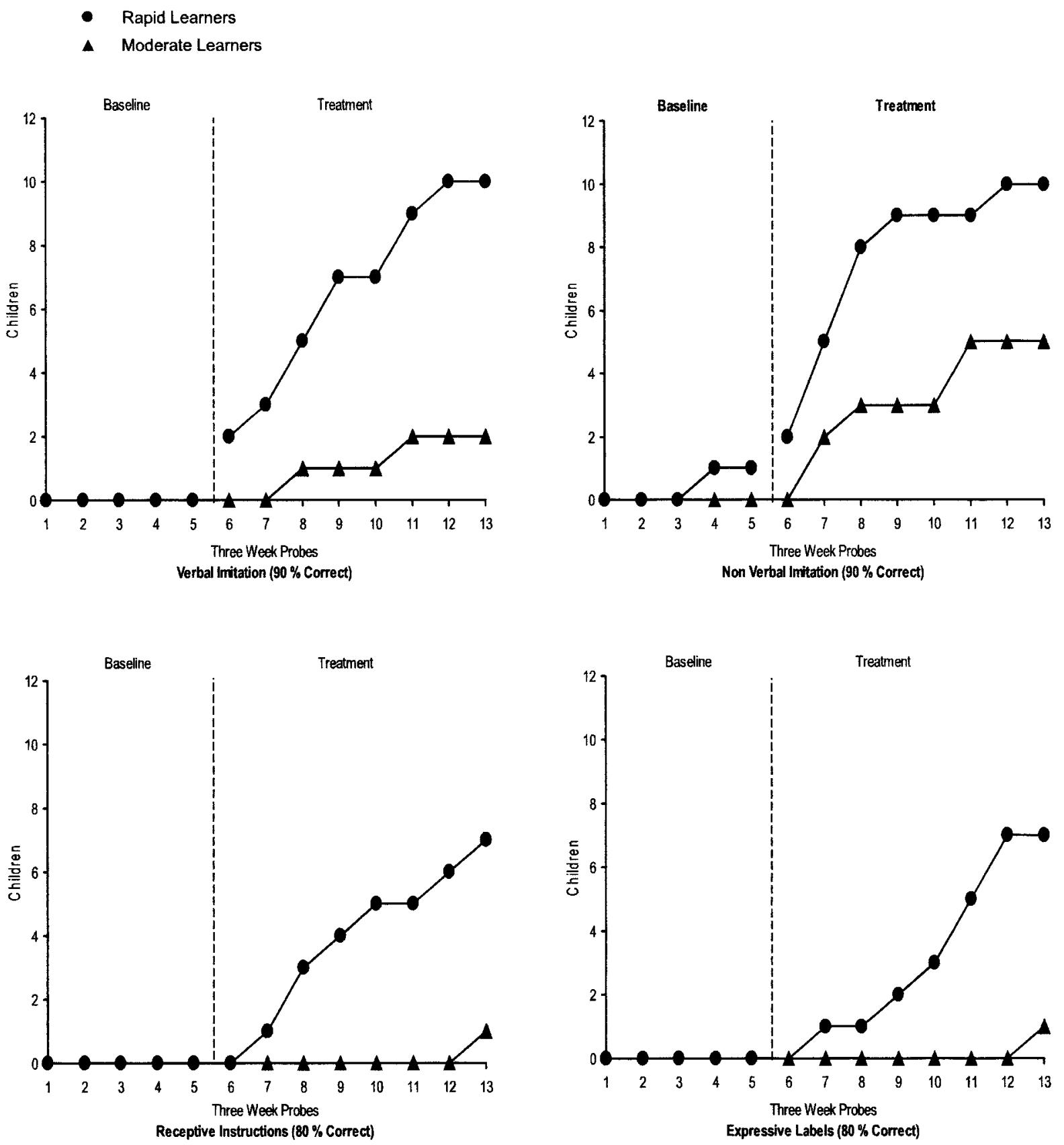

Figure 3. Performance of rapid (RL) and moderate (ML) learners on the Early Learning Measure.

We used linear regression using the best subset approach (Hosmer et al., 1989) to select the most powerful predictors for each outcome area. Based on previous research, potential predictor variables included IQ, imitation, language, social relatedness, and severity of symptoms. Posttreatment IQ was best predicted by the subset of variables including pretreatment Early Learning Mea- sure (receptive language, nonverbal imitation, and verbal imitation), pretreatment IQ, Autism Diagnostic Interview Impairment in Social Interaction (low social interest, unresponsive to others' approaches, lack of shared attention), and Autism Diagnostic Interview Communication scores. This set of variables yielded a correlation of .83 with posttreatment IQ, which is a strong relationship. 
Table 7. Correlations Between Pretreatment and Posttreatment Measures

\begin{tabular}{|c|c|c|c|c|c|}
\hline \multirow[b]{3}{*}{ Pretreatment measure ${ }^{a}$} & \multicolumn{5}{|c|}{ Follow-up } \\
\hline & \multicolumn{2}{|c|}{ One year } & \multicolumn{3}{|c|}{ Three year } \\
\hline & IQ & IQ change & IQ & Language & Social \\
\hline \multicolumn{6}{|l|}{ Reynell } \\
\hline Expressive & $.46^{*}$ & .37 & .35 & .41 & $.45^{*}$ \\
\hline Comprehension & .30 & .19 & .24 & .27 & .31 \\
\hline \multicolumn{6}{|l|}{ ELM } \\
\hline Nonverbal Imitation & $.59 * *$ & .41 & $.71 * *$ & $.69 * *$ & $.81 * *$ \\
\hline Exp. Labeling & $.48 *$ & $.54^{*}$ & $.46^{*}$ & $.56 * *$ & $.65 * *$ \\
\hline Rec. Instructions & $.47 *$ & .27 & $.56 * *$ & $.56 * *$ & $.67 * *$ \\
\hline Verbal Imitation & $.62 * *$ & $.59 * *$ & $.65^{* *}$ & $.69 * *$ & $.80 * *$ \\
\hline \multicolumn{6}{|l|}{ VABS } \\
\hline Communication & $.49 *$ & .35 & .33 & $.44^{*}$ & .41 \\
\hline $\mathrm{DLS}^{\mathrm{b}}$ & $.57 *$ & .40 & $.57 * *$ & $.60 * *$ & $.63 * *$ \\
\hline Motor & .36 & .16 & .17 & .22 & .27 \\
\hline Socialization & $.44^{*}$ & .31 & $.41 *$ & $.43^{*}$ & $.47 *$ \\
\hline Composite & $.56^{*}$ & .32 & .37 & $.43^{*}$ & $.46 *$ \\
\hline Merrill-Palmer IQ & .20 & -.01 & .08 & .06 & -.07 \\
\hline Bayley Ratio IQ & $.51 *$ & -.01 & $.45^{*}$ & .34 & .28 \\
\hline \multicolumn{6}{|l|}{ ADI-R } \\
\hline Communication & $-.49 *$ & -.35 & $-.59 * *$ & $-.52 *$ & $-.57 * *$ \\
\hline Socialization & -.22 & -.18 & $-.63 * *$ & $-.50 *$ & $-.52 *$ \\
\hline Ritualistic & -.12 & -.17 & -.12 & -.10 & -.10 \\
\hline First year IQ change & $.86 * *$ & - & $.87^{* *}$ & $.92 * *$ & $.82 * *$ \\
\hline IQ at one year & - & $.86 * *$ & $.75 * *$ & $.84 * *$ & $.75^{* *}$ \\
\hline
\end{tabular}

${ }^{a}$ Reynell $=$ Reynell Developmental Language Scales, ELM $=$ Early Learning Measure, VABS $=$ Vineland Adaptive Behavior Scales, ADI-R = Autism Diagnostic Interview-Revised. ${ }^{b}$ Daily Living Skills.

$* p<.05 . * p<.01$.

The amount of variation in posttreatment IQ explained by this subset of pretreatment variables was $70 \%$.

Social skill acquisition was also predicted by the pretreatment ability to imitate. The subset of variables, including pretreatment Early Learning Measure scores (receptive language, nonverbal imitation, and verbal imitation) and Autism Diagnostic Interview Communication yielded a correlation of .90 with posttreatment social skill scores, a strong relationship. The amount of variance in posttreatment social skill scores explained by this subset of pretreatment variables was $82 \%$.

Finally, language skill acquisition was also predicted by the pretreatment ability to imitate. The subset of variables including pretreatment Early Learning Measure scores (receptive language, non- verbal imitation, and verbal imitation), Vineland Daily Living Skills, and Autism Diagnostic Interview Communication yielded a correlation of .87 with posttreatment language scores, a strong relationship. The amount of variance in posttreatment language scores explained by this subset of pretreatment variables was $75 \%$.

Parents of 6 children (26\%) reported acquisition of 5 to 25 words, all of which were later lost between 15 and 26 months of age. Language regression in other studies has varied between 20\% and 50\% (Howlin, 1998), with a mean near 30\% (Shinnar et al., 2001) and median age of 18 months (Tuchman \& Rapin, 1997). Shinnar et al. reported that among those children who regained some language, only $8 \%$ achieved typical language. In the present study, loss of speech was not 
related to outcome. Three rapid learners and 3 moderate learners had a clear loss, and 6 rapid learners and 2 moderate learners had no loss (Rapid Learners vs. Moderate Learners $\times$ Pre- vs. Posttreatment, $\chi^{2}(1, N=14)=.16$, ns. Three of 6 children with clear regression (50\%) achieved typical language. However, having no speech at the start of treatment (age 36 months), whether from earlier loss (and not having recovered any) or never having developed speech, was associated with slower learning.

We used logistic regression to develop models to predict the probability of achieving 3-year outcome scores in the average range based on pretreatment measures. The most accurate model for the current set of data combined pretreatment Verbal Imitation from the Early Learning Measure and pretreatment Autism Diagnostic Interview Communication as follows: $p /(1-p)=e^{\mathrm{y}}$, where $e$ $=$ (approximately) 2.718284 and $y=[1.76$ (total verbal imitation items correct out of 20 trials from standard set administered three times, 3 weeks apart) -2.64 (Autism Diagnostic Interview-Communication score) +32.57$]$. Using a score above 0.5 to classify children as potentially "best outcome," this model correctly predicted 10 of 11 such children (sensitivity $=10 / 11=.91$ ), with one false positive and one false negative (specificity $=21 / 23=.91$ ). Predictive power was .91.

Hours of treatment. Table 8 shows the distri- bution of direct intervention hours for rapid learners during treatment. Most children received predominantly 1:1 intervention during the first year, and then gradually spent more time in school. Once children were able to use language, treatment was focused increasingly on building the social skills necessary to function in school and to interact with peers.

The number of weekly hours of treatment seemed less related to outcome than did pretreatment variables. Rapid learners averaged 34 hours per week during the first year (range $=25$ to 40 ) and 31 during the second year (range $=20$ to 39). Those who learned at a more moderate rate had identical averages, although they had less peer play due to limited play and language skills.

The hours shown in Table 8 do not include time spent by parents generalizing gains made in therapy, which they found quite difficult to estimate. In an effort to assess the impact of parental involvement, senior therapists rated parents on the percentage of involvement in their child's treatment during the first year. Although the correlation with outcome, $r=.32$, was not significant, the real impact of parental involvement may not be seen until formal treatment has ceased, when parents who were more involved all along and, therefore, acquired more skills, may be better prepared to help their child deal with new challenges.

Table 8. Average Allocation of Treatment Hours Over Time for Rapid Learners

\begin{tabular}{lccccccccc}
\hline & \multicolumn{8}{c}{ Years of treatment } \\
\cline { 2 - 10 } Staffing & .5 & 1 & 1.5 & 2 & 2.5 & 3 & 3.5 & 4 & 4.5 \\
\hline$n$ & 11 & 11 & 10 & 8 & 7 & 7 & 7 & 6 & 6 \\
$1: 1$ & 33 & 29 & 24 & 22 & 20 & 18 & 15 & 12 & 10 \\
& $(15-40)$ & $(16-35)$ & $(10-33)$ & $(15-31)$ & $(10-27)$ & $(5-28)$ & $(0-25)$ & $(4-25)$ & $(0-15)$ \\
School & 5 & 6 & 8 & 8 & 12 & 13 & 18 & 28 & 33 \\
& $(0-12)$ & $(0-12)$ & $(0-25)$ & $(0-16)$ & $(8-20)$ & $(8-25)$ & $(8-30)$ & $(15-35)$ & $(25-35)$ \\
School shadow & 1 & 1 & 4 & 5 & 8 & 11 & 7 & 5 & 5 \\
& $(0-5)$ & $(0-5)$ & $(0-15)$ & $(0-15)$ & $(3-15)$ & $(6-18)$ & $(0-18)$ & $(0-12)$ & $(2-15)$ \\
Peer shadow & 0 & 3 & 3 & 6 & 5 & 4 & 4 & 3 & 2 \\
& $(0)$ & $(0-5)$ & $(0-5)$ & $(2-9)$ & $(0-9)$ & $(0-8)$ & $(2-8)$ & $(0-6)$ & $(0-4)$ \\
Total & 34 & 33 & 31 & 33 & 33 & 33 & 26 & 21 & 17 \\
& $(25-40)$ & $(26-40)$ & $(20-37)$ & $(20-39)$ & $(25-37)$ & $(20-40)$ & $(7-40)$ & $(6-31)$ & $(12-20)$ \\
\hline
\end{tabular}

Note. Ranges are in parentheses. Total hours include school hours only when a shadow was present. Hours are for children still in treatment at each point in time. One child transferred to another provider after 1 year. Children began "graduating" from treatment after 2 years. Children who had difficulty learning complex material maintained full hours longer, but treatment focused more on 1:1 hours to teach skills and less on peer interaction due to lower social interest and language delays. 
Among rapid learners, the number of hours of structured home-based peer play was significantly related to teachers' ratings of social skills at 4 years. Although most children began peer play by 48 months of age, those who were subsequently rated by teachers as being within the average range (Vineland Socialization score of at least 90, and no Child Behavior Checklist scores over 65 on Scale 1 (Withdrawn) or Scale 4 (Social Problems), had several things in common. By age 54 months, they were all receiving at least 6 (mean $=8$ ) hours of supervised peer play per week with at least two unfamiliar peers (i.e., not siblings or cousins), and this continued for at least 6 months $(M=13), p=.008$ (Fisher Exact Test).

Supplemental treatments. Of the 23 children participating, 22 received some type of supplemental treatment prior to or during the first year of treatment (19 of 23 children). These services consisted of special education (21), preschool (2), and private therapies beyond what was offered in school: speech (5), sensory integration (7), auditory integration training (2), music therapy (1), and horseback riding (1). Hours per week of supplemental treatment ranged from 0 to 14 (average $=6$ ) prior to and 0 to 15 (average $=7$ ) hours during the first year of treatment. Between the first and third year of treatment, biomedical management became more popular, and more parents tried them. Nine children were on Gluten-Casein free diets (for 1 month to 21 months), 10 received mega-vitamins and/or dimethylglycine-DMG (for 1 month to 3 years), 4 received Secretin (1 to 4 doses), 4 were given Nystatin (for 1 month to 12 months), and 1 received 20 doses of Intravenous Immune Globulin. However, the correlation between hours of supplemental treatment and outcome $(-.335$ with IQ, -.384 with language, and -.334 with socialization) and that between the use of biomedical treatments and outcome $(-.050$ with IQ, -.108 with language, and -.141 with socialization) were low and not significant, supporting the conclusion that the increases in skills observed in this study were not the result of these interventions.

\section{Discussion}

In the present study we demonstrated that the UCLA early intensive behavioral treatment program could be implemented in a clinical setting outside a university with a similar sample and that the earlier findings by the UCLA group regarding favorable outcome (Lovaas, 1987; McEachin et al., 1993) could in large part be replicated without aversives. Following 2 to 4 years of treatment, 11 of 23 children (48\%) achieved Full Scale IQs in the average range, with IQ increases from 55 to 104 , as well as increases in language and adaptive areas comparable to data from the UCLA project. At age 7 , these rapid learners were succeeding in regular first or second grade classes, demonstrated generally average academic abilities, spoke fluently, and had peers with whom they played regularly.

Parent-directed children, who received 6 hours per month of supervision (usually 3 hours every other week, which is much more than "parent-managed" or "workshop" supervision), did about as well as clinic-directed children, although they received much less supervision. This was unexpected, and it may have been due in part to parent-directed parents taking on the senior therapist role, filling cancelled shifts themselves, actively targeting generalization, and pursuing teachers and neighbors to find peers for daily play dates with their children. Although many parentdirected parents initially made decisions regarding treatment that resulted in their children progressing slowly (e.g., using their treatment hours for ineffective interventions or pushing children to learn advanced skills before they were ready), resulting in frustration and occasionally "shutting down," many parents then sought input from treatment supervisors and rapidly learned to avoid making the same mistake twice, becoming quite skillful after a few months.

Several measures were used to assess residual symptoms of autism among rapid learners, and while generally not clinically significant, some were found, particularly among those children who achieved average IQ after several years of treatment. About one third of the rapid learners were seen as having mild delays in social skills. Seeming preoccupied was also a common problem for which 3 children were assigned classroom aides because they "needed reminders to stay on task." Lovaas (1987) did not mention that aides were assigned to any of his "best outcome" children, and it is possible that our children were not as "normal." However, McEachin et al. (1993) found that in spite of scoring in the clinically significant range in one or two areas, children were able to maintain their skills, scoring in the average range on standardized tests of cognitive, emotion$\mathrm{al}$, and social variables and to succeed in regular 
classes at follow-up 6 years after treatment was stopped.

The strongest pretreatment predictors of outcome were imitation, language, daily living skills, and socialization. Rapid acquisition of new material as measured by the Early Learning Measure, first year IQ, and change in IQ after 1 year were also strong predictors. These findings are consistent with previous research. A model with 91\% accuracy was derived for predicting whether a child in the present sample would be a rapid or moderate learner. The usefulness of the model must await validation with other similar samples. We note that one of the two predictors in the model was pretreatment verbal imitation, which is not widespread among untreated 3-year-old children with autism. However, the model may not discriminate among children above some as yet undetermined age because they often acquire imitation by school age (Charman et al., 1997).

Because we used the Bayley to determine pretreatment IQ and Wechsler tests at follow-up, there was a possibility that the observed increases in IQ may have reflected the use of different tests instead of treatment effects. To examine this, we compared changes in scores over time from Bayley at Time 1 to Bayley at Time 2, with changes from Bayley at Time 1 to Wechsler test at Time 2. One rapid learner was tested using the Bayley at pretreatment and again after 1 year of treatment because he was still only 3 years old. His score increased from 44 to 97, similar to increases seen in rapid learners tested with the Bayley at pretreatment and the WPPSI-R at 1 year. Ten moderate learners were tested using the Bayley at pretreatment and again after 1 year of treatment, and with Wechsler tests thereafter. For these children, Bayley to Bayley IQs increased from 47.2 to 54.3. Bayley to Wechsler IQs increased from 53.7 to 54.6. Therefore, there did not seem to be an effect on IQs attributable to using different tests.

Another possible confound was that most pre- and posttesting of moderate learners was done by the second author, perhaps introducing bias. However, the correlation between scores obtained by the second author and unaffiliated community psychologists was high, and the finding of little improvement over time on standardized tests for children in this subgroup is consistent with previous findings. A related question is whether the positive findings among rapid learners were due to treatment or maturation. Arguing against the maturation hypothesis is the negligible im- provement of children receiving community services found in several longitudinal studies (Eikeseth et al., 2002; Lord \& Schopler, 1989; Lovaas, 1987; Sheinkopf \& Siegel, 1998).

Although we matched on age and IQ and employed random assignment, this was not sufficient to ensure equal samples. Other pretreatment variables, such as imitation, correlated even more strongly with outcome and were not equal in the two groups. As a result, we were unable to interpret treatment effects among subgroups of rapid learners. Further, the small number of children in the study limited the power of statistical tests to detect differences, and the many tests on such a small sample increased the likelihood of spurious findings, thereby limiting the implications of results for the larger population of children with autism. However, because some treatment effects were so large and have been found in other studies (e.g., that a subset of the children do well), the current results can be seen as supporting an existing body of research.

We found two interesting correlations that deserve further study. First, ratings of parental involvement were weakly related to outcome, suggesting that more overt efforts to increase parents feeling capable of contributing to treatment planning may enhance treatment effects (Ramey et al., 1992). Second, acquisition of social skills was positively related to amount and duration of supervised peer play. Some parents were uncomfortable approaching other parents to set up play dates, and problems doing so may provide a partial explanation for the lower social skills scores of their children. Even so, amount and duration of supervised peer play are surely just a few of the variables that affect acquisition of social skills. Although we do have several powerful interventions, including incidental teaching, role playing, and video modeling, to teach a curriculum of social conversation, cooperative play, and understanding the nonverbal communication of others, building typical social skills remains a work in progress (McConnell, 2002).

Hours of treatment in this study came closer than any previous replication to the intensity of hours provided in the UCLA study (Lovaas, 1987), averaging 38 hours per week for 2 years in the clinic-directed group, and the results were also the most comparable. Forty-eight percent of the children showed dramatic increases in cognitive and social skills and were able to succeed in regular education classes. However, high hours and 
intensive supervision were not sufficient to make up for low levels of pretreatment skills. Consistent with previous studies, low IQ (below 44) and absence of language (no words at 36 months) predicted limited progress, whereas rate of learning, imitation. and social relatedness predicted favorable outcomes (Lord, 1995). Although starting at a disadvantage, children learning at a moderate rate were still acquiring new skills after 4 years. We intend to follow all of the children for several more years to determine their outcome in adolescence and adulthood.

\section{References}

Achenbach, T. M. (1991a). Child Behavior Checklist. Burlington: University of Vermont Department of Psychiatry. (Available from ASEBA, 1 S. Prospect St., Burlington, VT O5401-3456 and online at http://checklist. uvm.edu)

Achenbach, T. M. (1991b). Manual for the Teacher's Report Form and 1991 Profile. Burlington: University of Vermont Department of Psychiatry. (Available from ASEBA, 1 S. Prospect St., Burlington, VT O5401-3456, and online at http://checklist.uvm.edu)

American Psychiatric Association. (1994). Diagnostic and statistical manual of mental disorders (4th ed.). Washington, DC: American Psychiatric Association.

Anderson, S. R., Avery, D. L., DiPietro, E. K., Edwards, G. L., \& Christian, W. P. (1987). Intensive home-based intervention with autistic children. Education and Treatment of Children, 10, 352-366.

Bayley, N. (1993). Bayley Scales of Infant Development (2nd ed.). San Antonio: Psychological Corp.

Bibby, P., Eikeseth, S., Martin, N. T., Mudford, O. C., \& Reeves, D. (2002). Progress and outcomes for children with autism receiving parent-managed intensive interventions. Research in Developmental Disabilities, 23, 81-104.

Bierman, K. L., \& Welsh, J. A. (1997). Social relationship deficits. In E. J. Mash \& L. G. Terdal (Eds.), Assessment of childhood disorders (3rd ed., pp. 328-365). New York: Guilford Press.

Birnbrauer, J. S., \& Leach, D. J. (1993). The Murdoch Early Intervention Program after 2 years. Behavior Change, 10, 63-74.

Bondy, A., \& Frost, L. (1994). The Picture-Ex- change Communication System. Focus on $\mathrm{Au}$ tistic Behavior, 9, 1-19.

Bono, M. A., Daley, T., \& Sigman, M. (2004). Relations among joint attention, amount of intervention and language gain in autism. Journal of Autism and Developmental Disorders, 34, 495-505.

Carr, E. G., \& Durand, V. M. (1985). Reducing behavior problems through functional communication training. Journal of Applied Behavior Analysis, 18, 111-126.

Charlop, M. H., \& Milstein, J. P. (1989). Teaching autistic children conversational speech using video modeling. Journal of Applied Behavior Analysis, 22, 245-285.

Charman, T., Swettenham, J., Baron-Cohen, S., Cox, A., Baird, G., \& Drew, A. (1997). Infants with autism: An investigation of empathy, pretend play, joint attention, and imitation. Developmental Psychology, 33, 781-789.

Dawson, G., \& Osterling, J. (1997). Early intervention in autism. In M. Guralnick (Ed.), The effectiveness of early intervention. Baltimore: Brookes.

Eikeseth, S., Smith, T., Jahr, E., \& Eldevik, S. (2002). Intensive behavioral treatment at school for 4- to 7-year-old children with autism: A one-year comparison controlled study. Behavior Modification, 26, 49-68.

Eldevik, S., Eikeseth, S., Jahr, E., \& Smith, T. (in press). Effects of low-intensity behavioral treatment for children with autism and mental retardation. Journal of Autism and Developmental Disorders.

Fenske, B. C., Zalenski, S., Krantz, P. J., \& McClannahan, L. E. (1985). Age at intervention and treatment outcome for autistic children in a comprehensive intervention program. Analysis and Intervention in Developmental Disabilities, 5, 49-58.

Gray, C. (1994). The social story book. Arlington, TX: Future Horizons.

Green, G. (1996). Early behavioral intervention for autism: What does research tell us? In C. Maurice, G. Green, \& S. C. Luce (Eds.), Behavioral intervention for young children with autism (pp. 29-44). Austin, TX: Pro-Ed.

Gresham, F. M., \& MacMillan, D. L. (1998). Early intervention project: Can its claims be substantiated and its effects replicated? Journal of Autism and Developmental Disorders, 28, 5-13.

Harris, S. L., \& Handleman, J. S. (2000). Age and IQ at intake as predictors of placement for 
young children with autism: A four- to sixyear follow up. Journal of Autism and Developmental Disorders, 30, 137-142.

Harris, S. L., Handleman, J. S., Gordon, R., Kristoff, B., \& Fuentes, F. (1991). Changes in cognitive and language functioning of preschool children with autism. Journal of Autism and Developmental Disorders, 21, 281-290.

Hart, B., \& Risley, T. R. (1975). Incidental teaching of language in the preschool. Journal of Applied Behavior Analysis, 8, 411-420.

Hosmer, D. W., Jovanovic, B., \& Lemeshow, S. (1989). Best subset logistic regression. Biometrics, 45, 1265-1270.

Howard, J. S., Sparkman, C. R., Cohen, H. G., Green, G., \& Stanislaw, H. (2005). A comparison of intensive behavior analytic and eclectic treatments for young children with autism. Research in Developmental Disabilities, 26, 359383.

Howlin, P. (1998). Children with autism and Asperger syndrome: A guide for practitioners and carers. Chichester, West Sussex, England: Wiley.

Jacobson, J. W., Mulick, J. A., \& Green, G. (1998). Cost-benefit estimates for early intensive behavioral intervention for young children with autism: General models and single state case. Behavioral Interventions, 13, 201-226.

Jahr, E., Eldevik, S., \& Eikeseth, S. (2000). Teaching autistic children to initiate and sustain cooperative play. Research in Developmental Disabilities, 21, 151-169.

Koegel, L. K., Koegel, R. L., Shoshan, Y., \& McNerney, E. (1999). Pivotal response intervention II: Preliminary long-term outcomes data. Journal of the Association for Persons with Severe Handicaps, 24, 186-198.

Koegel, R. L., \& Koegel, L. K. (1995). Teaching children with autism: Strategies for initiating positive interactions and improving learning opportunities. Baltimore: Brookes.

Koegel, R. L., Russo, D. C., \& Rincover, A. (1977). Assessing and training teachers in the generalized use of behavioral modification with autistic children. Journal of Applied Behavior Analysis, 10, 197-205.

Lachar, D. (1982). Personality Inventory for Children (PIC): Revised format manual supplement. Los Angeles: Western Psychological Services.

Lord, C. (1995). Follow-up of two-year-olds referred for possible autism. Journal of Child Psychology and Psychiatry, 36, 1365-1382.

Lord, C., \& Paul, R. (1997). Language and com- munication in autism. In D. L. Cohen \& F. R. Volkmar (Eds.), Handbook of autism and pervasive developmental disorders (2nd ed., pp. 195-225). New York: Wiley.

Lord, C., Rutter, M., \& LeCouteur, A. (1994). Autism Diagnostic Interview-Revised: A revised version of a diagnostic interview for caregivers of individuals with possible pervasive developmental disorders. Journal of Autism and Developmental Disorders, 23, 659-685.

Lord, C., \& Schopler, E. (1989). The role of age at assessment, developmental level, and test in the stability of intelligence scores in young autistic children. Journal of Autism and Developmental Disorders, 19, 483-499.

Lovaas, O. I. (1987). Behavioral treatment and normal educational and intellectual functioning in young autistic children. Journal of Consulting and Clinical Psychology, 55, 3-9.

Lovaas, O. I., Ackerman, A. B., Alexander, D., Firestone, P., Perkins, J., \& Young, D. (1981). Teaching developmentally disabled children: The me book. Austin, TX: Pro-Ed.

Lovaas, O. I., Koegel, R. L., Simmons, J. Q., \& Long, J. S. (1973). Some generalization and follow-up measures on autistic children in behavior therapy. Journal of Applied Behavior Analysis, 6, 131-166.

Lovaas, O. I., \& Smith, T. (1988). Intensive behavioral treatment for young children with autism. In B. B. Lahey \& A. E. Kazdin (Eds.), Advances in clinical child psychology (Vol. 11, pp. 285-324). New York: Plenum.

Lovaas, O. I., Smith, T., \& McEachin, J. J. (1989). Clarifying comments on the young autism study: Reply to Schopler, Short and Mesibov. Journal of Consulting and Clinical Psychology, 57, 165-167.

Maine Administrators of Service for Children with Disabilities. (2000). Report of the $M A D$ SEC autism task force. Manchester, ME: Author. (Available online at http://www.madex. org)

Maurice, C., Green, G., \& Luce, S. C. (Eds.). (1996). Behavioral intervention for young children with autism. Austin, TX: Pro-Ed.

McConnell, S. R. (2002). Interventions to facilitate social interaction for young children with autism: Review of available research and recommendations for educational intervention and future research. Journal of Autism and Developmental Disorders, 32, 351-372.

McEachin, J. J., Smith, T., \& Lovaas, O. I. (1993). 
Long-term outcome for children with autism who received early intensive behavioral treatment. American Journal on Mental Retardation, 97, 359-372.

Meyer, L. S., Taylor, B. A., Levin, L., \& Fisher, J. R. (2001). Alpine Learning Group. In J. S. Handleman \& S. L. Harris (Eds.), Preschool education programs for children with autism (2nd ed., pp. 135-155). Austin, TX: Pro-Ed.

Mundy, P. (1993). Normal versus high-functioning status in children with autism. American Journal on Mental Retardation, 97, 381-384.

Newsom, C., \& Rincover, A. (1989). Autism. In E. J. Mash \& R. A. Barkley (Eds.), Treatment of childhood disorders (pp. 286-346). New York: Guilford.

New York State Department of Health, Early Intervention Program. (1999, May). Clinical practice guidelines: Autism/pervasive developmental disorders, assessment and intervention for young children (ages $0-3$ years). Albany: Author.

Ramey, C. T., Bryant, D. M., Wasik, B. H., Sparling, J. J., Fendt, K. H., \& LaVange, L. M. (1992). Infant health and development program for low birth weight, premature infants: Program elements, family participation, and child intelligence. Pediatrics, 3, 454-465.

Reynell, J. K., \& Gruber, G. P. (1990). Reynell Developmental Language Scales. Los Angeles: Western Psychological Services.

Roid, G. H., \& Miller, L. J. (1995, 1997). Leiter International Performance Scale-Revised. Wood Dale, IL: Stoelting.

Romanczyk, R. G., Lockshin, S. B., \& Matey, L. (2001). In J. S. Handleman \& S. L. Harris (Eds.), Preschool education programs for children with autism (2nd ed., pp. 49-94). Austin, TX: Pro-Ed.

Schopler, E., Short, A., \& Mesibov, G. (1989). Relation of behavioral treatment to normal functioning: Comment on Lovaas. Journal of Consulting and Clinical Psychology, 57, 162-164.

Schreibman, L. (1997). Theoretical perspectives on behavioral intervention for individuals with autism. In D. L. Cohen \& F. R. Volkmar (Eds.), Handbook of autism and pervasive developmental disorders (2nd ed., pp. 920-933). New York: Wiley.

Schreibman, L. (1988). Autism. Newbury Park, CA: Sage.

Semel, E., Wiig, E. H., \& Secord, W. A. (1995). Clinical evaluation of language fundamentals (3rd ed.). San Antonio: Psychological Corp.

(C) American Association on Mental Retardation
Sheinkopf, S. J., \& Siegel, B. (1998). Home-based behavioral treatment of young children with autism. Journal of Autism and Developmental Disorders, 28, 15-23.

Shinnar, S., Rapin, I., Arnold, S., Tuchman, R. F., Shulman, L., Ballaban-Gil, K., Maw, M., Deuel, R. K., \& Volkmar, F. R. (2001). Language regression in childhood. Pediatric Neurology, 24, 183-189.

Smith, T. (1993). Autism. In T. R. Giles (Ed.), Handbook of effective psychotherapy (pp. 107133). New York: Plenum.

Smith, T., Buch, G. A., \& Gamby, T. E. (2000). Parent-directed, intensive early intervention for children with pervasive developmental disorder. Research in Developmental Disabilities, 21, 297-309.

Smith, T., Eikeseth, S., Klevstrand, M., \& Lovaas, O. I. (1997). Intensive behavioral treatment for preschoolers with severe mental retardation and pervasive developmental disorder. American Journal on Mental Retardation, 102, 238-249.

Smith, T., Groen, A., \& Wynn, J. (2000). Randomized trial of intensive early intervention for children with pervasive developmental disorder. American Journal on Mental Retardation, 105, 269-285.

Smith, T., \& Lovaas, O. I. (1997). The UCLA Young Autism Project: A reply to Gresham and McMillan. Behavioral Disorders, 22, 202218.

Smith, T., McEachin, J. J., \& Lovaas, O. I. (1993). Comments on replication and evaluation of outcome. American Journal on Mental Retardation, 97, 385-391.

Sparrow, S. S., Balla, D. A., \& Cicchetti, D. V. (1984). Vineland Adaptive Behavior Scales (Interview Ed.). Circle Pines, MN: American Guidance Service.

Stutsman, R. (1948). Merrill Palmer Scale of Mental Tests. Wood Dale, IL: Stoelting.

Tuchman, R. F., \& Rapin, I. (1997). Regression in pervasive developmental disorders: Seizures and epileptiform electroencephalogram correlates. Pediatrics, 99, 560-566.

Venter, A., Lord, C., \& Schopler, E. (1992). A follow-up study of high-functioning autistic children. Journal of Child Psychology and Psychiatry, 33, 489-507.

Wechsler, D. (1989). Wechsler Preschool and Primary Scale of Intelligence-Revised. San Antonio, TX: Psychological Corp. 
Wechsler, D. (1991). Manual for the Wechsler Intelligence Scale for Children: Third Edition. San Antonio: Psychological Corp.

Weiss, M. J. (1999). Differential rates of skill acquisition and outcomes of early intensive behavioral intervention for autism. Behavioral Interventions, 14, 3-22.

Wirt, R. D., Lachar, D., Klinedinst, J. K., \& Seat, P. D. (1977). Multidimensional descriptions of child personality: A manual for the Personality Inventory for Children. Los Angeles: Western Psychological Services.

Woodcock, R. W., McGrew, K. S., \& Mather, N. (2001). Woodcock-Johnson III Tests of Achievement. Itasca, IL: Riverside.
Received 7/22/04, accepted 7/20/05.

Editor-in-charge: William E. MacLean, Jr.

This research was supported in part by National Institute of Mental Health Grant MH4886301A3, Multi-Site Young Autism Project. We thank Crystal (Burns) Held, the UCLA-trained clinic supervisor, for her efforts in carrying out this study; Tristram Smith for reviewing the manuscript multiple times; Robyn Dawes and Shuangge $\mathrm{Ma}$ for consultation on data analysis; and $\mathrm{O}$. Ivar Lovaas for the opportunity to train at UCLA, his mentorship, and support. Requests for reprints should be sent to either author at the Wisconsin Early Autism Project, 6402 Odana Rd., Madison, WI 53719. E-mail: weap@wiautism.com

\section{Errata}

Several errors occurred in the article "Support Needs and Adaptive Behaviors," by Julia Harries, Roma Guscia, Neil Kirby, Ted Nettelbeck, and John Taplin (Vol. 110, No. 5, 393-404). On page 395, in last line under Participants, the $S D$ should be 3.2 years not 3.2 months.

In Table 4 on page 400, there should not be a superscript $a$ next to the ICAP heading. Also, in this table the coefficient for SIS Health and Safety subscale in Factor 3 should be -.16 not .16.

In the reference list, there should be reference to two versions of the Supports Intensity Scale (one unpublished version and one published version) as follows:

Thompson, J. R., Bryant, B., Campbell, E. M., Craig, E. M., Hughes, C., Rotholz, D. A., Schalock, R. L., Silverman, W., Tassé, M. J., \& Wehmeyer, M. (2002). Supports Intensity Scale: Standardization and users manual. Unpublished assessment scale, American Association on Mental Retardation.

Thompson, J. R., Bryant, B., Campbell, E. M., Craig, E. M., Hughes, C., Rotholz, D. A., Schalock, R. L., Silverman, W., Tassé, M. J., \& Wehmeyer, M. (2004). Supports Intensity Scale: Users manual. Washington, DC: American Association on Mental Retardation. 